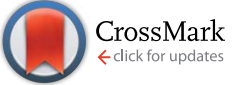

Cite this: J. Mater. Chem. A, 2017, 5, 201

Received 26th October 2016 Accepted 13th November 2016

DOI: 10.1039/c6ta09275f

www.rsc.org/MaterialsA

\section{Efficient photocatalytic reduction of dinitrogen to ammonia on bismuth monoxide quantum dots $\uparrow$}

\author{
Songmei Sun, ${ }^{a}$ Qi An, ${ }^{b}$ Wenzhong Wang, ${ }^{\text {*a }}$ Ling Zhang, ${ }^{a}$ Jianjun Liu*a \\ and William A. Goddard III
}

$\mathrm{N}_{2}$ reduction to ammonia by solar light represents a green and sustainable ammonia synthesis approach which helps to suppress the global warming and energy crisis. However, conventional semiconductors usually suffer from low activity or poor stability, largely suppressing the application of this technology. Here, we report that bismuth monoxide $(\mathrm{BiO})$ quantum dots with an average size of $2-5 \mathrm{~nm}$ exhibited efficient photocatalytic activity for ammonia synthesis under simulated solar light. A highly efficient ammonia synthesis rate of $1226 \mu \mathrm{mol} \mathrm{g}{ }^{-1} \mathrm{~h}^{-1}$ is achieved without the assistance of any sacrificial agent or co-catalyst, which is about 1000 times higher than that using the traditional $\mathrm{Fe}-\mathrm{TiO}_{2}$ photocatalyst. Kinetic analysis reveals that the synergy of three low valence surface Bi(I) species markedly enhances $\mathrm{N}_{2}$ activation by electron donation, which finally resulted in the highly efficient $N_{2}$ photoreduction performance. This work will shed light on designing efficient and robust $\mathrm{N}_{2}$ reduction photocatalysts.

\section{Introduction}

The reduction of dinitrogen $\left(\mathrm{N}_{2}\right)$ to ammonia is a requisite transformation for life growth and survival. ${ }^{1-4}$ Although over $78 \%$ of the atmosphere is composed of dinitrogen molecules, they are not used by most of the organisms due to the strong $\mathrm{N} \equiv \mathrm{N}$ bond, nonpolarity and high ionization potential. ${ }^{5,6} \mathrm{At}$ present, most of the required nitrogen for human beings is still originated from the energy-intensive Haber-Bosch ammonia synthesis process, ${ }^{7,8}$ which consumes $1-2 \%$ of the world's energy supply and generates more than 300 million tons of carbon dioxide annually. ${ }^{9-12}$ In contrast, dinitrogen photoreduction to ammonia by solar light represents a green and sustainable ammonia synthesis route without fossil fuel consumption and $\mathrm{CO}_{2}$ emission. ${ }^{\mathbf{1 3 - 1 6}}$ However, the state-of-theart efficiencies for ammonia synthesis by this approach are still far away from the industrial demand. ${ }^{\mathbf{1 7 - 2 4}}$

Generally, the rate-determining step for $\mathrm{N}_{2}$ reduction is cleavage of the $\mathrm{N} \equiv \mathrm{N}$ bond. ${ }^{5,6} \mathrm{~N}_{2}$ activation by electron donation from some reducing active sites is indispensable for the promotion of $\mathrm{N} \equiv \mathrm{N}$ bond cleavage, ${ }^{25}$ but such reducing active sites rarely exist on most of the semiconductor photocatalysts. Until now, the majority of the reported $\mathrm{N}_{2}$ photoreduction catalysts have only defect type activation centers, ${ }^{17-24}$ which

${ }^{a}$ State Key Laboratory of High Performance Ceramics and Superfine Microstructure, Shanghai Institute of Ceramics, Chinese Academy of Sciences, Shanghai 200050, P. R. China.E-mail:wzwang@mail.sic.ac.cn; jliu@mail.sic.ac.cn

${ }^{b}$ Division of Chemistry and Chemical Engineering, California Institute of Technology, Pasadena, California 91125, USA

$\dagger$ Electronic supplementary information (ESI) available: Fig. S1-S8. See DOI: $10.1039 /$ c6ta09275f result in unsatisfactory photocatalytic performance because of their limited defect concentrations. Besides, defect states often suffer from thermal instability and increased charge carrier recombination, which further prevent their practical application for artificial ammonia synthesis. Consequently, developing an ideal photocatalytic material which has a high concentration of non-defect type activation centers with robust stability holds the key to achieving a breakthrough in $\mathrm{N}_{2}$ photoreduction technology.

Using low valence metal species in low-valent metal oxide semiconductors for $\mathrm{N}_{2}$ activation may be a viable strategy to achieve this important goal. Low-valent metals in semiconductor solids have fewer coordination atoms than those in their high-valent state and are hence chemically unsaturated to facilitate chemisorption of molecules. ${ }^{26}$ Owing to the strong electron donating power, low-valent metal species such as Fe, Mo, $\mathrm{Zr}$, and $\mathrm{Ti}$ have been widely studied for $\mathrm{N}_{2}$ activation in organometallic complexes, ${ }^{\mathbf{9 , 1 6 , 2 7 - 3 0}}$ although a stoichiometric excess of strong reducing agents (such as $\mathrm{Na}, \mathrm{K}$ ) and extra proton sources are generally required to further generate $\mathrm{NH}_{3}$ in these reaction systems. Different from organometallic complexes, low-valent metal species in semiconductor materials may act as both $\mathrm{N}_{2}$ activation and hydrogenation centers without extra reducing agents, which allows quick reaction kinetics for $\mathrm{N}_{2}$ reduction, because the conduction band of a metal oxide semiconductor is usually hybridized by the metal p, d orbitals, ${ }^{31}$ and photogenerated electrons are mainly located on the metal sites. Moreover, different from defect-type active sites, lattice low-valent metal species can refrain from becoming an electron-hole recombination center and all of the surface low-valent metal sites could contribute to the catalysis reactions 
theoretically. In this regard, low-valent metal oxide semiconductors are expected to exhibit high photocatalytic activity for $\mathrm{N}_{2}$ photoreduction. To confirm this opinion, herein low valent bismuth monoxide (BiO) was selected as an ideal model material to study the $\mathrm{N}_{2}$ photoreduction performance. We focus on low valent bismuth(II) because it has high electron donating power and empty $6 \mathrm{~d}$ orbitals for $\mathrm{N}_{2}$ adsorption and activation. More importantly, bismuth based materials have been widely studied with various catalytic applications. ${ }^{32-34}$

\section{Experimental}

\section{Preparation of $\mathrm{BiO}$}

Firstly, sodium oleate $(2.2 \mathrm{mmol})$ and $\mathrm{Bi}\left(\mathrm{NO}_{3}\right)_{3} \cdot 5 \mathrm{H}_{2} \mathrm{O}$ $(0.4 \mathrm{mmol})$ were successively added to distilled water $(20 \mathrm{~mL})$. After vigorous stirring for $2 \mathrm{~h}, 20 \mathrm{~mL}$ water was added and the suspension was then transferred to a $50 \mathrm{~mL}$ Teflon-lined autoclave, sealed and heated at $140{ }^{\circ} \mathrm{C}$ for $17 \mathrm{~h}$. The system was then allowed to cool down to room temperature. The obtained solid products were collected by centrifugation, washed with absolute ethanol three times, and then freeze-dried for further characterization. For comparison, 0.2 wt\% Fe-doped $\mathrm{TiO}_{2}$ was prepared according to a previous report by coprecipitation and calcination process at $500{ }^{\circ} \mathrm{C}$ for $3 \mathrm{~h} .{ }^{18}$ The XRD pattern of the Fe-doped $\mathrm{TiO}_{2}$ is shown in Fig. S1.†

\section{Characterization}

The purity and crystallinity of the as-prepared samples were characterized by powder X-ray diffraction (XRD) on a Japan Rigaku Rotaflex diffractometer using $\mathrm{Cu} \mathrm{K} \alpha$ radiation while the voltage and electric current were held at $40 \mathrm{kV}$ and $100 \mathrm{~mA}$. The transmission electron microscopy (TEM) analyses were performed using a JEOL JEM-2100F field emission electron microscope. X-ray photoelectron spectroscopy (XPS) was carried out by irradiating the sample with a $320 \mu \mathrm{m}$ diameter spot of monochromated aluminum $\mathrm{K} \alpha \mathrm{X}$-rays at $1486.6 \mathrm{eV}$ under ultrahigh vacuum conditions (performed on an ESCALAB 250, Thermo Scientific Ltd). The UV-vis diffuse reflectance spectrum (DRS) of the sample was recorded using a Hitachi UV-3010PC UV-vis spectrophotometer. The Fourier transform infrared (FTIR) spectrum of the concentrated ammonia product was obtained using a spectrophotometer (Nicolet 380, Thermo, USA). Nitrogen temperatureprogrammed desorption ( $\left.\mathrm{N}_{2}-\mathrm{TPD}\right)$ measurements were performed on a ChemiSorb 2750 instrument. Typically, $20 \mathrm{mg}$ of the sample, placed in a glass tube, was pretreated by a He gas flow at $150^{\circ} \mathrm{C}$ for $2 \mathrm{~h}$, and then cooled down to $50{ }^{\circ} \mathrm{C}$. The adsorption of $\mathrm{N}_{2}$ was performed in a $99.999 \% \mathrm{~N}_{2}$ gas flow for $2 \mathrm{~h}$ at $50{ }^{\circ} \mathrm{C}$. After purging with $\mathrm{He}$ gas, the sample was heated from $50{ }^{\circ} \mathrm{C}$ to $450{ }^{\circ} \mathrm{C}$ at a rate of $10{ }^{\circ} \mathrm{C} \mathrm{min}^{-1}$. The TPD signal was recorded using a thermal conductivity detector. All gas flow rates were set as $30 \mathrm{~mL} \mathrm{~min} \mathrm{~m}^{-1}$ ${ }^{1} \mathrm{H}$ NMR spectra were acquired on a Bruker AV500 NMR spectrometer.

\section{Photocatalytic test}

Photocatalytic $\mathrm{N}_{2}$ reduction was performed using a $500 \mathrm{~W}$ Xe lamp located approximately $10 \mathrm{~cm}$ from the sample. The reaction cell (capacity $600 \mathrm{~mL}$ ) was made of Pyrex glass with a quartz window on top. For atmospheric $\mathrm{N}_{2}$ fixation, $0.05 \mathrm{~g}$ of the as-prepared photocatalyst powder was dispersed in $200 \mathrm{~mL}$ deionized water and then stirred under the simulated solar light irradiation. For ${ }^{15} \mathrm{~N}$ isotopic labelling experiment, the reaction cell was enclosed by a quartz window on top. $\mathrm{N}_{2}$ $\left(50 \%{ }^{15} \mathrm{~N}_{2}, 50 \%{ }^{14} \mathrm{~N}_{2}\right)$ gas was slowly bubbled through the reaction vessel, which contained $200 \mathrm{~mL}$ deionized water until it was saturated. Then the reaction vessel was sealed and irradiated under the simulated solar light irradiation. During the photocatalytic tests, the temperature of the reaction vessel was maintained at $25{ }^{\circ} \mathrm{C}$ by providing a flow of cooling water. The concentration of ammonia in the reactor solution was measured using the indophenol blue method. The amount of evolved $\mathrm{O}_{2}$ was determined by using online gas chromatography.

\section{Computational methods}

Periodic density functional theory (DFT) calculations with spinpolarization were performed using the VASP code. The nonlocal exchange and correlation energies were described using a generalized gradient approximation with the Perdew-BurkeErnzerhof (PBE) functional (PBE-GGA). The electron-ion interactions were described by the projector augmented wave (PAW) potential. The plane wave-plane basis set with an energy cutoff of $400 \mathrm{eV}$ and $4 \times 4 \times 4 k$-point Monkhorst-Pack grid were used in our calculations. The convergence criteria for electronic SCF and force were set as less than $1.0 \times 10^{-6} \mathrm{eV}$ and $0.01 \mathrm{eV} \AA^{-1}$, respectively.

\section{Electrochemical measurements}

Electrochemical measurements were performed on a CHI 660D electrochemical workstation (Shanghai Chenhua, China) using a standard three-electrode cell with a working electrode, a platinum wire as the counter electrode, and a standard saturated calomel electrode (SCE) in saturated $\mathrm{KCl}$ as the reference electrode. The working electrodes were prepared by dip-coating: briefly, $5 \mathrm{mg}$ of the photocatalyst was suspended in $0.1 \mathrm{~mL}$ of ethanol in the presence of $1 \%$ Nafion to produce a slurry, which was then dipcoated onto a $2 \mathrm{~cm} \times 1.5 \mathrm{~cm}$ FTO glass electrode and dried at $25^{\circ} \mathrm{C}$.

\section{Calculation of electron transfer number}

For an adsorption-controlled and irreversible electrode process, according to Laviron, ${ }^{35} E_{\mathrm{p}}$ is defined by the following equation:

$$
E_{\mathrm{p}}=E^{0}+(R T / a n F) \ln \left(R T k^{0} / a n F\right)+(R T / a n F) \ln v
$$

where $R$ is the molar gas constant, $T$ is the thermodynamic temperature, $F$ is the Faraday constant, $a$ is the transfer coefficient, $k^{0}$ is the standard rate constant of the reaction, $n$ is the electron transfer number involved in the rate-determining step, $\nu$ is the scan rate $\left(\mathrm{mV} \mathrm{s}^{-1}\right)$, and $E^{0}$ is the formal potential. For an irreversible electrode process, $a \approx 0.5$. 


\section{Results and discussion}

We designed an oleate-modified hydrothermal synthesis method to obtain the desired $\mathrm{BiO}$ material. Oleate ions played an important role in the formation of this low-valence bismuth oxide compound, as shown in Fig. 1. Initially each $\mathrm{Bi}^{3+}$ ion interacted electrostatically with three oleate ions to form Bi-oleate complexes, which then aggregated into larger Bi-oleate particles driven by the hydrophobic effect of the oleate tails. The presented extra oleate ions in the solution accumulated around the $\mathrm{Bi}$ oleate complex by means of hydrophobic carbon tails to form stable Bi-oleate micelles with a hydrophilic outer shell which dispersed homogeneously in the reaction solution. The BiO compound was nucleated through a dehydration and condensation reaction after permeation of a small amount of $\mathrm{OH}^{-}$into the $\mathrm{Bi}$-oleate micelles. This process was hindered by the strong steric effect from oleate, which has a long aliphatic carbon chain to prevent the entry of polar ions. Owing to the reductivity of unsaturated carbon-carbon double bonds in oleate, Bi(III) was gradually reduced to $\mathrm{Bi}$ (II) during reaction with $\mathrm{OH}^{-}$to form the low-valence $\mathrm{BiO}$ compound in the micelles. Without the addition of oleate ions, $\mathrm{Bi}_{2} \mathrm{O}_{3}$ is the final hydrothermally synthesized product. The as-prepared $\mathrm{BiO}$ compound exhibited quantum sized spherical-like morphology (quantum dots) with an average size of $2-5 \mathrm{~nm}$ (Fig. 2a). A high magnification TEM image (Fig. 2b) gives more details of the microstructure, which revealed

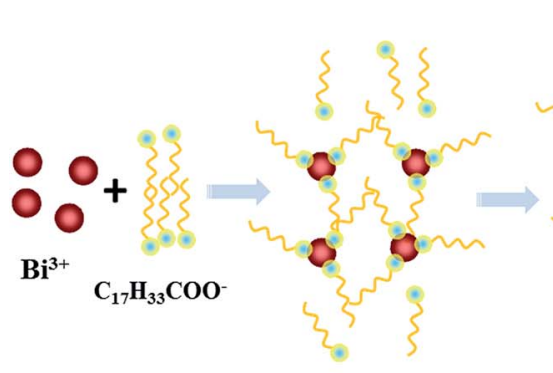

Bi-oleate complex

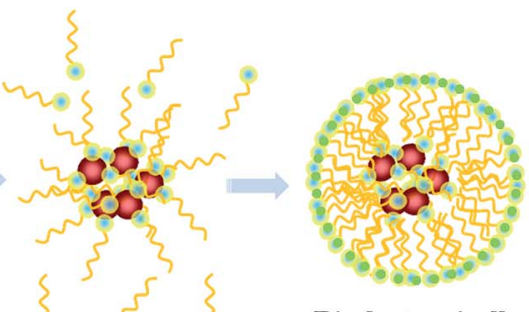

Bi-oleate micelle

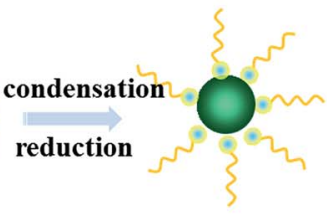

$\mathrm{BiO}$

Fig. 1 Schematic illustration of the whole synthesis procedure for the BiO quantum dots.

a

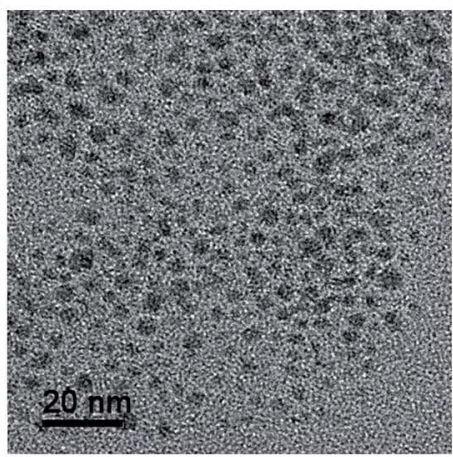

C

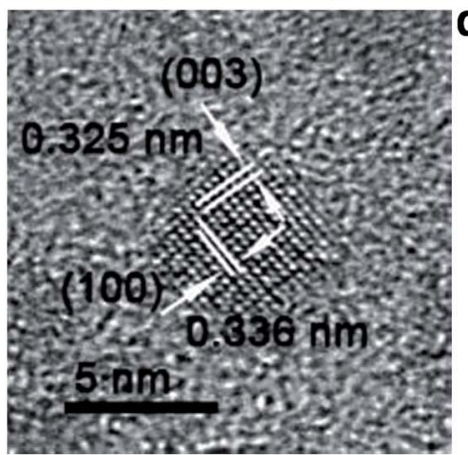

b

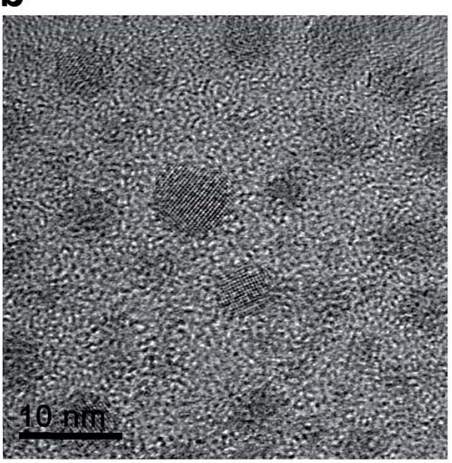

d

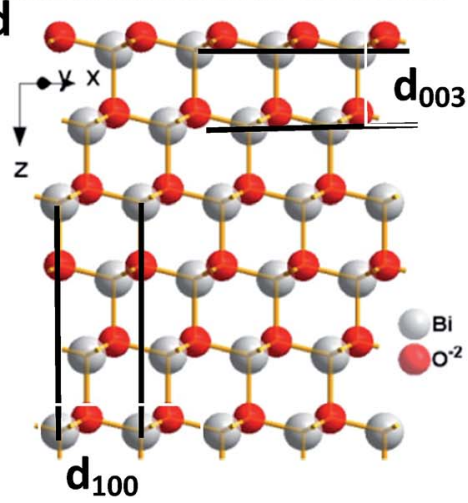

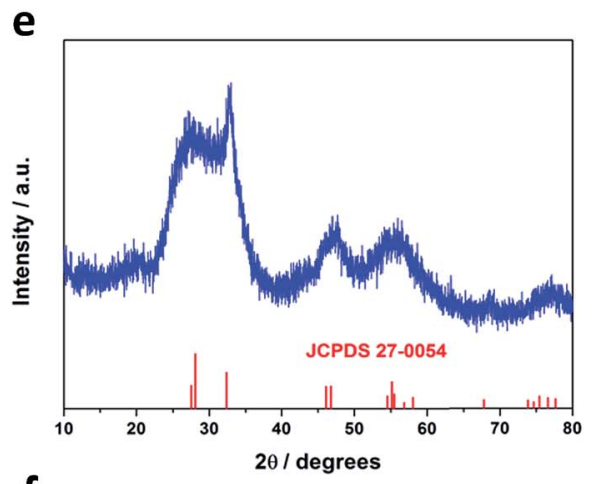

f

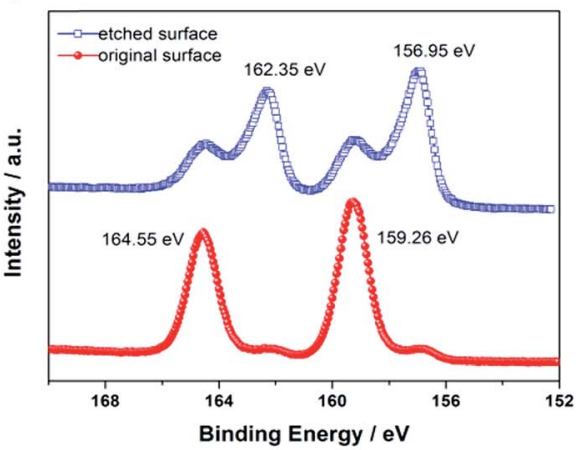

Fig. 2 Characterizations of the hydrothermally synthesized BiO sample. (a) Low magnification TEM image of the BiO sample. (b) High magnification TEM image. (c) High resolution TEM image. (d) The related schematic atomic model of BiO, clearly showing the atomic configuration of $\mathrm{Bi} / \mathrm{O}$ and the hexagonal tunnel structure along the [010] direction. (e) XRD pattern of the as-prepared BiO sample. (f) XPS spectrum of the as-prepared $\mathrm{BiO}$ sample in the $\mathrm{Bi} 4 \mathrm{f}_{5 / 2}$ and $\mathrm{Bi} 4 \mathrm{f}_{7 / 2}$ binding energy region. 
the single crystal nature of the BiO particles. From the high resolution TEM (HRTEM) image in Fig. 2c, (003) and (100) planes of BiO (space group $R 3 \mathrm{~m}$ ) with a $d$ spacing of 0.325 and $0.336 \mathrm{~nm}$ were clearly observed, which belong to the [010] zone axis of BiO. The schematic crystal structure of BiO along the [010] direction (Fig. 2d) displayed the same orientation and arrangement of (003) and (100) planes as that observed from Fig. 2c. The purity and crystallinity of the $\mathrm{BiO}$ particles were investigated using X-ray diffraction patterns. As shown in Fig. 2e, all of the diffraction peaks can be indexed to the hexagonal phase of BiO (JCPDS no. 27-0054). No other likely impurities, such as $\mathrm{Bi}_{2} \mathrm{O}_{3}$ or $\mathrm{Bi}(\mathrm{OH})_{3}$, were detected. The broad diffraction peaks were ascribed to its quantum size which is calculated to be about $3 \mathrm{~nm}$ in average based on the Scherrer equation. The XPS spectrum further confirmed the presence of this low-valent bismuth(II) monoxide compound. As shown in Fig. $2 \mathrm{f}$, the binding energies of $\mathrm{Bi} 4 \mathrm{f}_{5 / 2}$ and $\mathrm{Bi} 4 \mathrm{f}_{7 / 2}$ peaks of the original BiO surface are mainly located at $164.55 \mathrm{eV}$ and $159.26 \mathrm{eV}$ which originate from the residual surface-adsorbed Bi(III)-oleate precursor. However, in the case of an etched surface, the binding energies of the $\mathrm{Bi} 4 \mathrm{f}_{5 / 2}$ and $\mathrm{Bi} 4 \mathrm{f}_{7 / 2}$ peaks mainly decreased to $162.35 \mathrm{eV}$ and $156.95 \mathrm{eV}$, proving the existence of low-valent bismuth species on a cleaner BiO surface. The optical absorption property of the prepared BiO was investigated by UV-vis diffuse reflectance spectroscopy which exhibited an intense UV-vis light absorption at wavelengths shorter than $430 \mathrm{~nm}$ (Fig. S2†), indicating a band gap of $2.88 \mathrm{eV}$ for the BiO sample.

To study the photocatalytic $\mathrm{N}_{2}$ reduction property of the $\mathrm{BiO}$ catalyst, $0.05 \mathrm{~g}$ of the $\mathrm{BiO}$ particles was dispersed in $200 \mathrm{~mL}$ of deionized water and then subsequently irradiated under simulated solar light irradiation. Control experiments showed that $\mathrm{NH}_{4}{ }^{+}$cannot be generated in the absence of the BiO catalyst or solar light irradiation. In contrast, simulated solar light irradiation resulted in continuous ammonia generation by the BiO sample (Fig. 3a). After $24 \mathrm{~h}$ of irradiation, the BiO catalyst generated $7.4 \mathrm{mg} \mathrm{L}{ }^{-1}$ of $\mathrm{NH}_{4}{ }^{+}$from pure water in air. In an acidic reaction solution ( $\mathrm{pH} 3.8$ ) which could provide excess protons to decrease the kinetic barrier for $\mathrm{N}_{2}$ reduction, the generated ammonia concentration by the $\mathrm{BiO}$ catalyst was increased to $20.6 \mathrm{mg} \mathrm{L}^{-1}$ within $24 \mathrm{~h}$, with a much improved
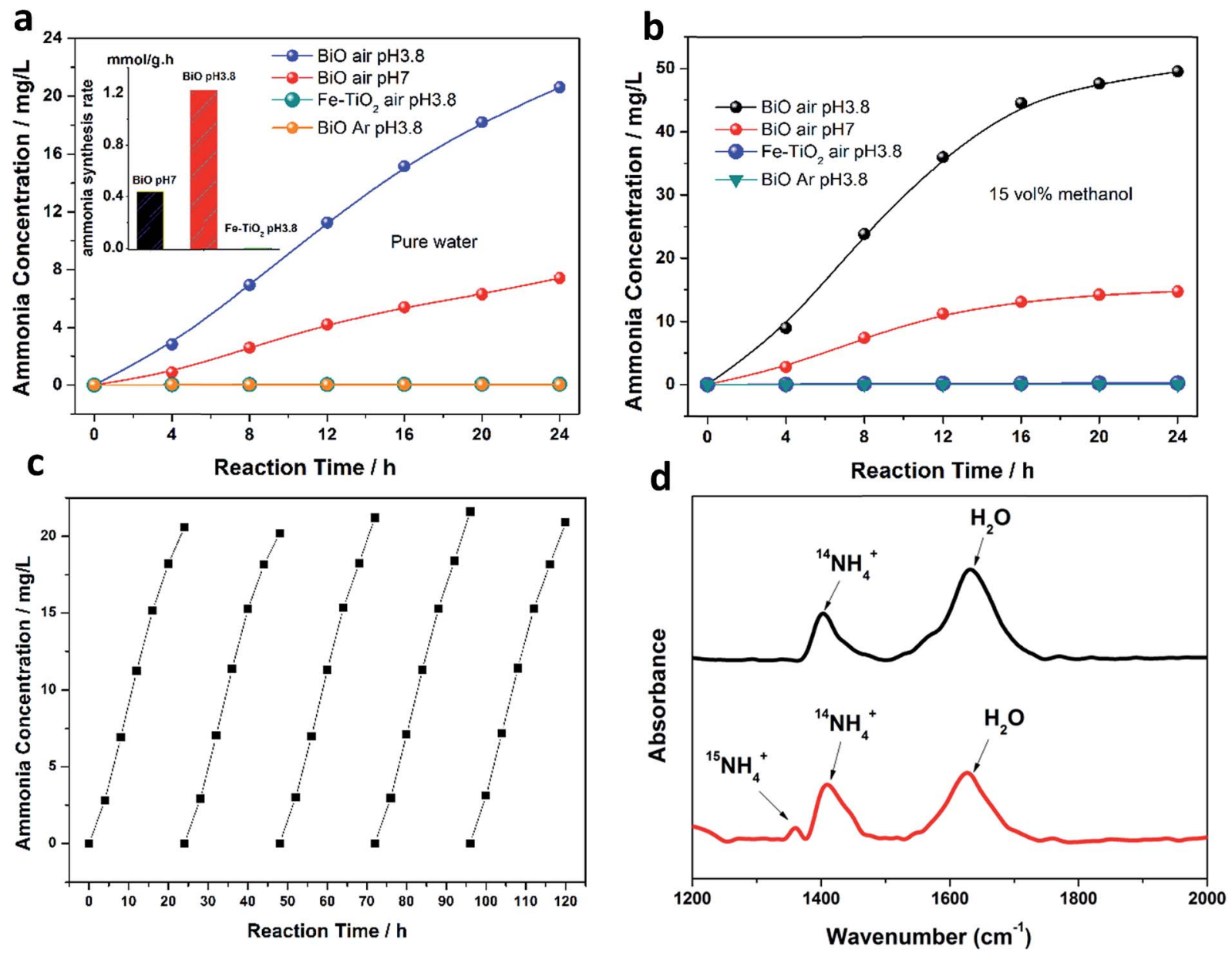

Fig. 3 Photocatalytic $\mathrm{N}_{2}$ reduction performance of the as-prepared BiO sample under different conditions and simulated solar light irradiation. (a) The generated ammonia concentrations at different irradiation times in pure water; inset: the corresponding ammonia synthesis rate. (b) The generated ammonia concentrations at different irradiation times in 15 vol\% methanol solution. (c) Photostability of the as-prepared BiO sample for $\mathrm{N}_{2}$ reduction under simulated solar light and acidic conditions $\left(\mathrm{pH}\right.$ 3.8). (d) Comparison of experimental infrared spectra of $\mathrm{NH}_{4}{ }^{+}$obtained after $\mathrm{N}_{2}$ photoreduction on the BiO catalyst using $50 \%{ }^{15} \mathrm{~N}_{2}$ labelled $\mathrm{N}_{2}$ and pure ${ }^{14} \mathrm{~N}_{2}$ respectively. 
ammonia synthesis rate of about $1226 \mu \mathrm{mol} \mathrm{g}{ }^{-1}$ (catalyst) $\mathrm{h}^{-1}$, 1000 times higher than that of the traditional $\mathrm{Fe}^{-\mathrm{TiO}_{2}}$ photocatalyst (Fig. 3a) under the same conditions. When the reaction was performed in $15 \%$ aqueous methanol, a known sacrificial electron donor, the ammonia synthesis rate was further significantly improved, producing a total $\mathrm{NH}_{4}{ }^{+}$amount of 0.7 mmol after $24 \mathrm{~h}$ (Fig. 3b), equivalent to a turnover number of 3.18. This suggests that ammonia evolution under these conditions is catalytic. The increase in the ammonia synthesis rate in aqueous methanol indicates that the BiO quantum dots are able to photooxidize methanol. Under the same conditions, no ammonia generation was detected with the BiO catalyst both in pure water and aqueous methanol in argon saturated solution, indicating that the ammonia in the reaction system originated from $\mathrm{N}_{2}$ reduction. The stability of the BiO catalyst under acidic conditions was also investigated. After 5 consecutive runs $(120 \mathrm{~h})$ for $\mathrm{N}_{2}$ reduction, the photocatalytic performance of the BiO particles was well-maintained (Fig. 3c). The TEM image of the BiO catalyst after the cycle of reaction also indicates the stability of the BiO catalyst (Fig. S3†).

To further confirm that the detected $\mathrm{NH}_{4}{ }^{+}$in our experiment indeed originated from $\mathrm{N}_{2}$ reduction, we performed an isotopic labelling study using $50 \mathrm{vol} \%{ }^{15} \mathrm{~N}_{2}$ as the purge gas. Infrared spectroscopy was used to characterize the $\mathrm{NH}_{4}{ }^{+}$product. The IR spectra (Fig. 3d) indicate that both ${ }^{15} \mathrm{NH}_{4}{ }^{+}$and ${ }^{14} \mathrm{NH}_{4}{ }^{+}$exist in the reaction solution when using $50 \%{ }^{15} \mathrm{~N}_{2}$ labelled $\mathrm{N}_{2}$, while only ${ }^{14} \mathrm{NH}_{4}{ }^{+}$is detected when using pure ${ }^{14} \mathrm{~N}_{2}$. The infrared absorption peak of ${ }^{14} \mathrm{NH}_{4}{ }^{+}$was located around $1405 \mathrm{~cm}^{-1}$, while the peak position for ${ }^{15} \mathrm{NH}_{4}{ }^{+}$is at $1358 \mathrm{~cm}^{-1}$ which is in good agreement with the value estimated according to the isotope effect (that is, $\left.1405 \mathrm{~cm}^{-1} \times(14 / 15)^{1 / 2}=1357 \mathrm{~cm}^{-1}\right) .{ }^{25}$ The isotope labelling study further proved that the $\mathrm{NH}_{4}{ }^{+}$originates from the photocatalytic $\mathrm{N}_{2}$ reduction process. ${ }^{1} \mathrm{H}$ NMR spectrum was also used for detecting the ${ }^{15} \mathrm{NH}_{4}{ }^{+}$species in the obtained ammonia product. As shown in Fig. $\mathrm{S} 4, \uparrow$ both ${ }^{15} \mathrm{NH}_{4}{ }^{+}$ and ${ }^{14} \mathrm{NH}_{4}{ }^{+}$were observed in the NMR spectrum. The ratio of the ${ }^{15} \mathrm{NH}_{4}{ }^{+}$content to ${ }^{14} \mathrm{NH}_{4}{ }^{+}$was about $2.7: 3$, which is close to the initial ${ }^{15} \mathrm{~N}_{2}$ ratio.

It is of significant importance to understand the underlying mechanism of the high photocatalytic activity of $\mathrm{BiO}$ in reducing $\mathrm{N}_{2}$ in order to develop other efficient photocatalysts. Quantum chemical calculations based on density functional theory (DFT) were conducted to investigate the possible $\mathrm{N}_{2}$ activation and hydrogenation process on the BiO catalyst. According to the experimental observation from the HRTEM image, a representative $\mathrm{BiO}\{010\}$ surface was selected to investigate the $\mathrm{N}_{2}$ activation and hydrogenation performance. First, the partial charge density of the nearby Fermi level was calculated to analyze the possible interaction positions of $\mathrm{BiO}$ surfaces with $\mathrm{N}_{2}$. As shown in Fig. $4 \mathrm{a}$ and $\mathrm{b}$, the valence bands of $\mathrm{BiO}$ near Fermi levels are mainly generated by p-electrons of $\mathrm{Bi}$ atoms. The charge distribution on $\mathrm{BiO}\{010\}$ surface is significantly localized and accumulated around $\mathrm{Bi}$ atoms, which indicates that $\mathrm{N}_{2}$ activation by electron donation may take place upon the $\mathrm{Bi}$ activation centers. The extent of $\mathrm{N}_{2}$ activation and hydrogenation on the BiO surface is reflected by the change of the $\mathrm{N}-\mathrm{N}$ bond length. Fig. 4c presents $\mathrm{N}-\mathrm{N}$ bond distance evolutions with addition of hydrogen atoms on the $\mathrm{BiO}\{010\}$ surfaces. For comparison, the corresponding evolutions without the catalyst are also plotted. As shown in Fig. 4c, the BiO $\{010\}$ surface displays high catalytic activity on activation of the $\mathrm{N} \equiv \mathrm{N}$ bond in $\mathrm{N}_{2} \mathrm{H}_{n}(n=0-3)$. The $\mathrm{N}-\mathrm{N}$ bond length could be elongated from $1.09 \AA$ to $1.12 \AA$ when it is near the $\mathrm{BiO}\{010\}$ surface. The $\mathrm{N}-\mathrm{N}$ bond length could be further increased along with hydrogenation until three $\mathrm{H}$ atoms were hydrogenated, indicating that the $\mathrm{N} \equiv \mathrm{N}$ bond may be broken after three $\mathrm{H}$ atoms were added by the $\mathrm{BiO}$ catalyst. Considering that the $\mathrm{N}_{2}$ photoreduction experiment was performed in water in this study, the influence of water molecules on the $\mathrm{N}_{2}$ activation and hydrogenation was also investigated. The calculated result indicates that the catalytic activity of $\mathrm{BiO}$ was not changed with addition of $\mathrm{H}_{2} \mathrm{O}$ on the surface. In addition, $\mathrm{H}_{2} \mathrm{O}$ molecules covering the surface can quickly dissociate into $\mathrm{H}^{+}$and $\mathrm{OH}^{-}$, providing sufficient hydrogen for ammonia generation. Besides, the binding energy calculations reveal a weaker interaction between $\mathrm{N}_{2} \mathrm{H}_{n}$ and the water-covered $\mathrm{BiO}$ surface than that on a dry surface (Fig. 4d). This indicates that water on the $\mathrm{BiO}\{010\}$ surface is advantageous to improve $\mathrm{N}_{2}$ photoreduction performance since hydrogenated $\mathrm{N}_{2} \mathrm{H}_{n}$ can easily be desorbed from the catalyst. Temperature programmed desorption (TPD) investigation was also conducted to visualize the adsorption and activation of $\mathrm{N}_{2}$ on the surface of the BiO catalyst. As shown in Fig. S5, $\dagger$ two peaks at $295^{\circ} \mathrm{C}$ and $330^{\circ} \mathrm{C}$ were clearly observed for $\mathrm{N}_{2}$ desorption, which indicated the excellent $\mathrm{N}_{2}$ chemisorption on the BiO catalyst.

Photoelectrochemical measurements further revealed the possible reasons for the high performance of the BiO catalyst. As shown in Fig. 5a, two well-defined cathodic peaks around $-0.7 \mathrm{~V}$ and $-1.2 \mathrm{~V}$ appear in the cyclic voltammetry experiments in $\mathrm{N}_{2}$ saturated $0.5 \mathrm{M} \mathrm{Na}_{2} \mathrm{SO}_{4}$ solution for the BiO electrode in an acidic solution $(\mathrm{pH}=3.8)$, the $\mathrm{pH}$ value of which was adjusted using dilute $\mathrm{H}_{2} \mathrm{SO}_{4}$. The lower reduction peak around $-0.7 \mathrm{~V}$ arises only after the electro-reduction process proceeds for a certain length of time (Fig. $5 \mathrm{a}$ and $56 \dagger$ ), indicating that this reduction peak may have originated from further reduction of intermediates during the photoelectrochemical process. Therefore the $\mathrm{N}_{2}$ reduction peak around $-1.2 \mathrm{~V}\left(E_{\mathrm{p}}\right)$ was adopted for the kinetic study under acidic conditions. As shown in Fig. 5a, the peak current densities increased with increase in the scan rates $(\nu)$. The electron transfer number $(n)$ involved in the $\mathrm{N}_{2}$ reduction can be calculated from the slope of $E_{\mathrm{p}}-\ln \nu$. The value of $n$ was calculated to be 2.93 at the potential of 20-100 $\mathrm{mV}$, indicating that a possible one-step three electron transfer $\mathrm{N}_{2}$ reduction process may occur on the BiO surface. As is well known, nitrogen fixation is a proton-coupled reaction. ${ }^{36}$ Although the BiO surface could provide sufficient low valence $\mathrm{Bi}(\mathrm{II})$ activation centers, excess $\mathrm{H}^{+}$is also important to realize a proton coupled multi-electron reduction process. In a neutral reaction solution, the electron transfer number was decreased to 1.34 based on the analysis of the reduction peak around -0.9 $\mathrm{V}$ (Fig. 5b), indicating that $\mathrm{N}_{2}$ reduction on the BiO catalyst in neutral solution may be realized through six consecutive oneelectron redox steps, resulting in a much lower ammonia synthesis rate. This is in line with the observed lower 

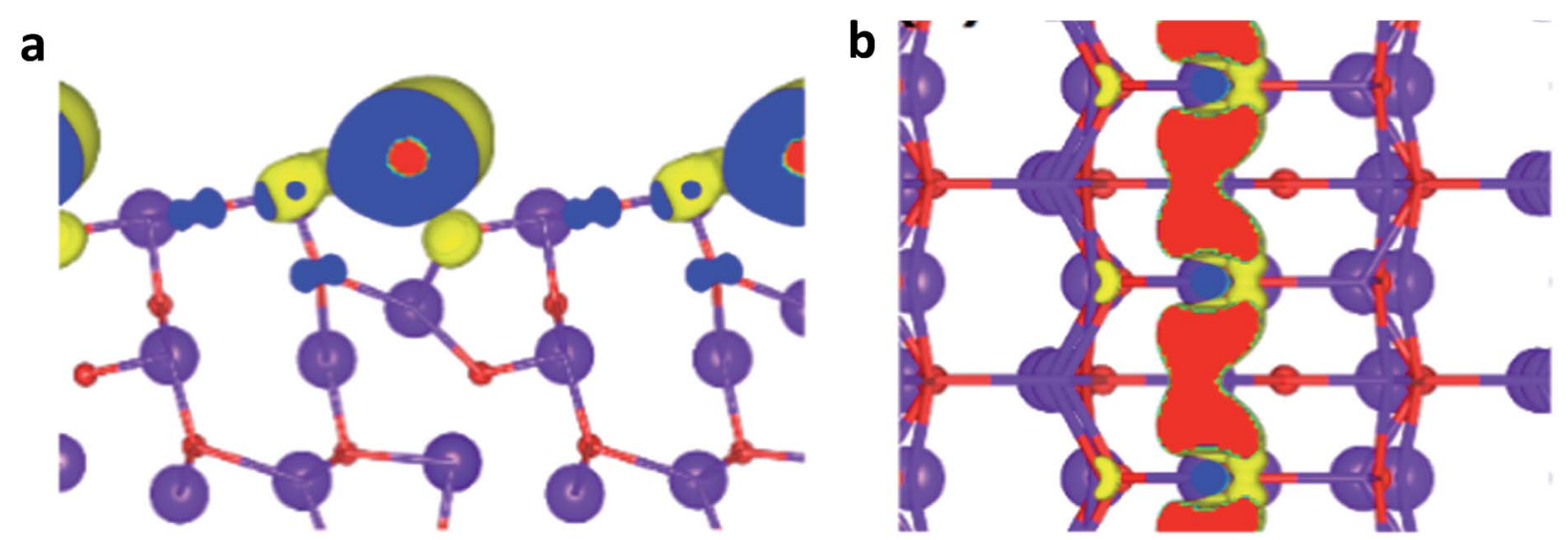

C

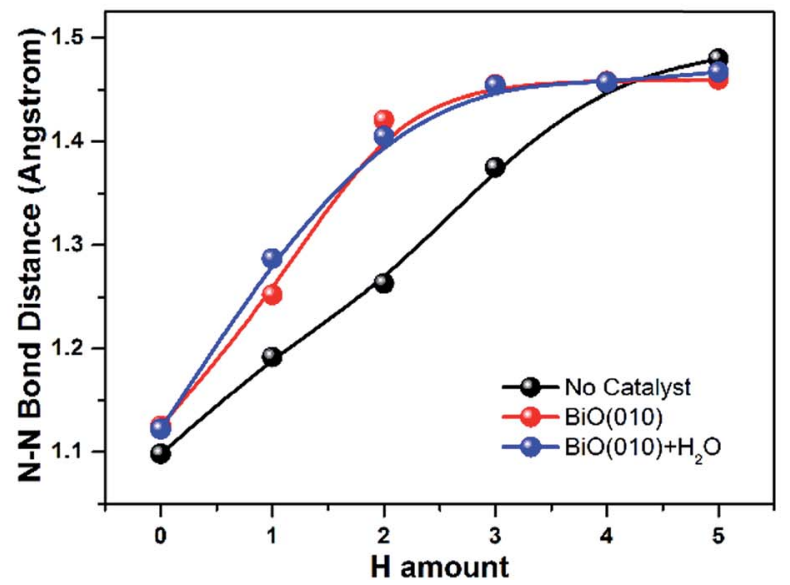

d

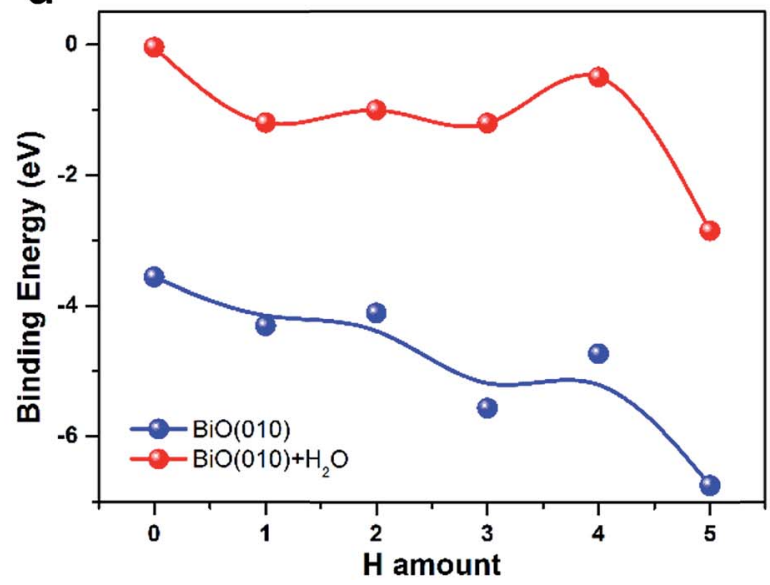

Fig. 4 Quantum chemical calculations of $\mathrm{N}_{2}$ activation and hydrogenation performance of the BiO catalyst based on density functional theory. ( $a$ and $b$ ) The calculated charge density plot at the valence band maximum (VBM) of BiO $\{010\}$ surfaces; $a$ : top view and b: side view. The yellow and blue isosurfaces represent charge accumulation and depletion in the space, respectively. (c) The $\mathrm{N}-\mathrm{N}$ bond distance evolutions with addition of hydrogen atoms on $\mathrm{BiO}\{010\}$ surface. (d) The binding energy of $\mathrm{N}_{2} \mathrm{H}_{n}$ on $\mathrm{BiO}\{010\}$ surface.

photocatalytic $\mathrm{N}_{2}$ reduction activity at $\mathrm{pH}=7$. Besides, a decreased cathodic current density (Fig. $5 \mathrm{c}$ ) in a $\mathrm{N}_{2}$-saturated reaction system was observed when compared with that in air saturated solution, which proved that a larger number of electrons were transferred from the $\mathrm{BiO}$ catalyst to the $\mathrm{N}_{2}$ molecule in the $\mathrm{N}_{2}$-saturated reaction system under the same conditions. Fig. 5d shows the Mott-Schottky spectrum of the BiO sample, which is usually used for the analysis of the flat band potential $\left(E_{\mathrm{fb}}\right)$ of semiconductor electrodes. ${ }^{37}$ The positive slope of the plot indicates that the BiO catalyst is an n-type semiconductor with electrons as the majority charge carriers. The $E_{\mathrm{fb}}$ value which was calculated from the intercept of the axis with potential values was at $-0.69 \mathrm{~V} v s$. SCE. For many n-type semiconductors, $E_{\mathrm{fb}}$ is considered to be about $0.1 \mathrm{~V}$ below the conduction band $\left(E_{\mathrm{cb}}\right) \cdot{ }^{38}$ Based on this, the estimated $E_{\mathrm{cb}}$ value of the BiO sample was $-0.55 \mathrm{~V}$ vs. NHE. According to the thermodynamic data of $\mathrm{N}_{2} \mathrm{H}_{3}$ reported by Bauer, ${ }^{39}$ the $\mathrm{N}_{2}$ reduction potential via $\mathrm{N}_{2}+3 \mathrm{H}^{+}+3 \mathrm{e}^{-} \rightarrow \mathrm{N}_{2} \mathrm{H}_{3}$ is not larger than $-0.485 \mathrm{~V}$ vs. NHE. This indicates that the photogenerated electrons in the BiO catalyst could energetically reduce the $\mathrm{N}_{2}$ molecule via a proton-coupled three-electron reduction process. Besides, the valence band potential of the BiO catalyst, which was estimated from the band gap and $E_{\mathrm{cb}}$, was also energetically large enough $(2.39 \mathrm{~V} v s$. NHE) for water oxidation $(1.23 \mathrm{~V} v s$. NHE) under acidic conditions, indicating that water could efficiently act as a sacrificial electron donor for ammonia generation. All of these studies proved the possibility of a highly efficient one-step three-electron $\mathrm{N}_{2}$ reduction on the BiO catalyst, which may be realized by the synergy of three adjacent low valence $\mathrm{Bi}(\mathrm{II})$ activation centers. This process does not occur easily in a traditional $\mathrm{N}_{2}$ reduction photocatalyst, which only has isolated defect-type activation centers.

The crystal structure and coordination environment of the BiO compound may play an important role in its highly efficient photocatalytic $\mathrm{N}_{2}$ reduction performance. As shown in Fig. 2d, the BiO compound exhibits a hexagonal tunnel structure along the [010] direction, which is built up from three alternately arranged Bi groups and $O$ groups. The entrance diameter of this tunnel structure is about 4.4-4.7 $\AA$, large enough for structurally filling one $\mathrm{N}_{2}$ molecule (diameter $3 \AA$ ). A careful observation of the local structure of $\mathrm{BiO}$ indicates that $\mathrm{BiO}_{4}$ presents a pyramidal unit with two $\angle \mathrm{OBiO}$ angles of $114.2^{\circ}$ and $104.2^{\circ}$, far from a tetrahedral structure (Fig. S7 $\dagger$ ). This indicates that bismuth atoms may undergo an orbital hybridization of $\mathrm{sp}^{3} \mathrm{~d}$ 

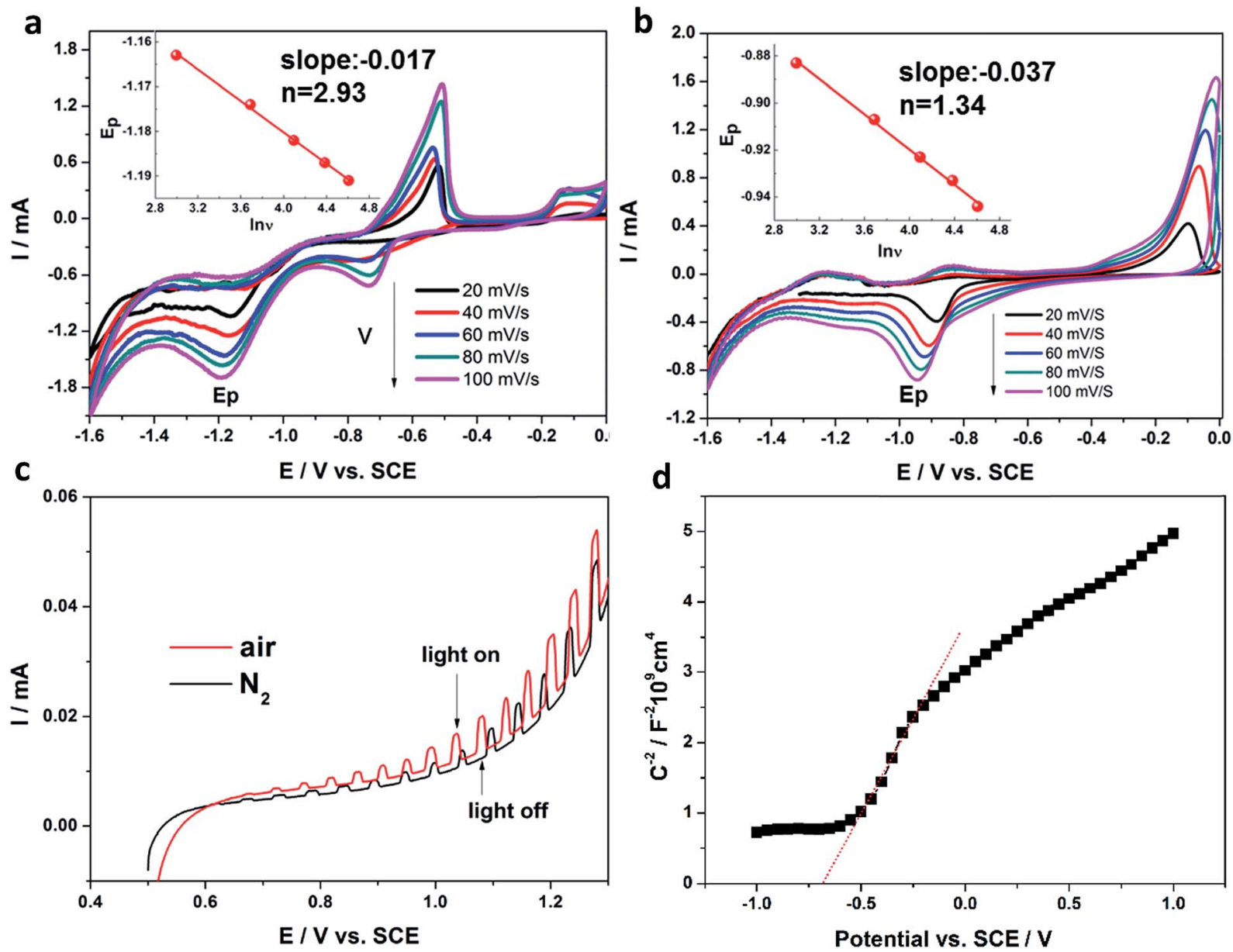

Fig. 5 Kinetic study of $\mathrm{N}_{2}$ reduction on the BiO catalyst by electrochemical measurements in $\mathrm{N}_{2}$ saturated $0.5 \mathrm{M} \mathrm{Na}_{2} \mathrm{SO}_{4}$ under room temperature $\left(25^{\circ} \mathrm{C}\right)$ and simulated solar light irradiation. (a) Cyclic voltammograms of the BiO electrode at $\mathrm{pH}=3.8$. (b) Cyclic voltammograms of the $\mathrm{BiO}$ electrode at $\mathrm{pH}=7$. Inset: plot of reduction peak potential $\left(E_{\mathrm{p}}\right)$ vs. In $\nu$ (scan rate). (c) Cathodic electrochemical scans on the asprepared $\mathrm{BiO}$ electrode under chopped simulated solar light irradiation. (d) Mott-Schottky plot of the as-prepared $\mathrm{BiO}$ electrode in $0.5 \mathrm{M} \mathrm{Na}_{2} \mathrm{SO}_{4}$ at $\mathrm{pH}=7$.

resulting in the orbital distribution of a trigonal bipyramid, leaving a lone pair of electrons on the Bi atom. The $\mathrm{N}_{2}$ molecule may be stretched and activated by three alternatively arranged Bi atoms through donating electrons to the empty $6 \mathrm{~d}$ orbitals of $\mathrm{Bi}$ atom and accepting electrons from the lone pairs of Bi atom to its three unoccupied anti-bonding orbitals $\left(\pi^{*} 2 \mathrm{p}_{y}, \pi^{*} 2 \mathrm{p}_{z}\right.$ and $\sigma^{*} 2 \mathrm{p}_{x}$ ), resulting in a $1 \mathrm{~N}_{2}-3 \mathrm{Bi}$ side-on bond structure (Fig. $6 \mathrm{a}$ ). The electron donations from the three adjacent low valence bismuth ions will strongly weaken the $\mathrm{N} \equiv \mathrm{N}$ bond, which facilitates a one-step three electron $\mathrm{N}_{2}$ reduction process in a successive photocatalytic process by proton and electron transfer (Fig. 6b).

Based on the above analysis, the possible $\mathrm{N}_{2}$ reduction reactions on $\mathrm{BiO}$ surface under acidic conditions are proposed as follows.

$$
\begin{gathered}
\mathrm{BiO}+h v \rightarrow \mathrm{BiO}\left(\mathrm{h}^{+}+\mathrm{e}^{-}\right) \\
\mathrm{N}_{2}+3 \mathrm{BiO}\left(\mathrm{e}^{-}\right)+3 \mathrm{H}^{+} \rightarrow \mathrm{N}_{2} \mathrm{H}_{3} \\
\mathrm{~N}_{2} \mathrm{H}_{3}+3 \mathrm{BiO}\left(\mathrm{e}^{-}\right)+5 \mathrm{H}^{+} \rightarrow 2 \mathrm{NH}_{4}^{+}
\end{gathered}
$$

$$
\begin{gathered}
\mathrm{N}_{2} \mathrm{H}_{3}+\mathrm{BiO}\left(\mathrm{e}^{-}\right)+\mathrm{H}^{+} \rightarrow \mathrm{N}_{2} \mathrm{H}_{4} \\
2 \mathrm{~N}_{2} \mathrm{H}_{3} \rightarrow 2 \mathrm{~N}_{2}+3 \mathrm{H}_{2} \\
3 \mathrm{H}_{2} \mathrm{O}+6 \mathrm{BiO}\left(\mathrm{h}^{+}\right) \rightarrow 3 / 2 \mathrm{O}_{2}+6 \mathrm{H}^{+}
\end{gathered}
$$

First, simulated solar light excited electrons and holes are generated on the BiO catalyst (eqn (1)). Then the photogenerated electrons may transfer to the surface and participate in a one-step three electron $\mathrm{N}_{2}$ reduction process to obtain an $\mathrm{N}_{2} \mathrm{H}_{3}$ intermediate (eqn (2)) due to the possible $1 \mathrm{~N}_{2}-3$ Bi side-on bond structure. The $\mathrm{N}_{2} \mathrm{H}_{3}$ intermediate will be further reduced to $\mathrm{NH}_{4}{ }^{+}$(eqn (3)) or $\mathrm{N}_{2} \mathrm{H}_{4}$ (eqn (4)) by a subsequent one step three-electron or one-electron photocatalytic reduction process, respectively. Otherwise, the $\mathrm{N}_{2} \mathrm{H}_{3}$ intermediate will be decomposed, because it is a short-lived, endothermic compound. ${ }^{39,40}$ If the $\mathrm{N}_{2} \mathrm{H}_{3}$ intermediate is not further reduced, it will decompose into $\mathrm{N}_{2}$ and $\mathrm{H}_{2}$ spontaneously (eqn (5)). In our experiment, the reaction rates of eqn (2) and (3) may be much higher than that of eqn (5), resulting in continuous production of $\mathrm{NH}_{4}{ }^{+}$under 


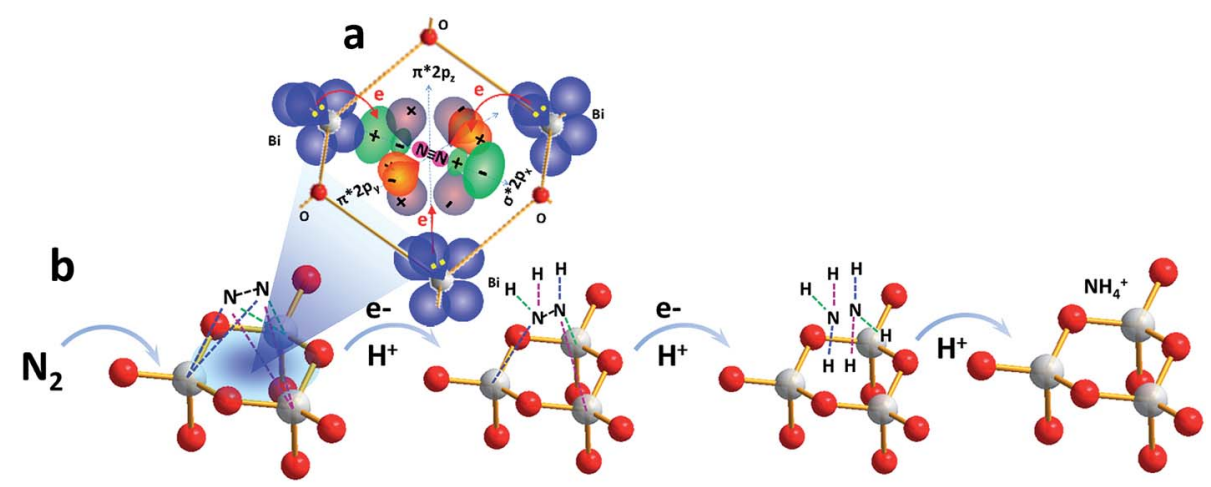

Fig. 6 Possible pathway for $\mathrm{N}_{2}$ activation and hydrogenation on the BiO catalyst. (a) Schematic electron donation from the lone pairs of three Bi atoms to the three unoccupied anti-bonding orbitals $\left(\sigma^{*} 2 p_{x}, \pi * 2 p_{y}\right.$, and $\left.\pi * 2 p_{z}\right)$ of the $N_{2}$ molecule, forming a $1 N_{2}-3 B i(\|)$ side-on bond structure. (b) The whole $\mathrm{N}_{2}$ activation and reduction process on the $\mathrm{BiO}$ catalyst.

the acidic conditions. The amount of $\mathrm{N}_{2} \mathrm{H}_{4}$ in the final product was only about $1.6 \%$, possibly because of the $1 \mathrm{~N}_{2}-3 \mathrm{Bi}$ side-on coordinating mode of $\mathrm{N}_{2}$ which facilitates the three-electron reduction process (eqn (2) and (3)). During the photocatalytic $\mathrm{N}_{2}$ reduction process, $\mathrm{O}_{2}$ was produced from water oxidation by photogenerated holes (eqn (6)). The theoretical molar ratio of the generated $\mathrm{NH}_{4}{ }^{+}$to $\mathrm{O}_{2}$ from the above equations is 1.33. In a closed reaction system filled with pure $\mathrm{N}_{2}$ and water, we observed continuous $\mathrm{O}_{2}$ evolution (Fig. S8†) along with prolonged irradiation time and a total amount of $117 \mu \mathrm{mol} \mathrm{O} \mathrm{O}_{2}$ was obtained when generating $2.32 \mathrm{mg} \mathrm{NH}_{4}{ }^{+}$. The molar ratio of the generated $\mathrm{NH}_{4}{ }^{+}$to $\mathrm{O}_{2}$ is 1.41 , which is close to the theoretical value. Besides, a tiny amount of $\mathrm{H}_{2}(2.4 \mu \mathrm{mol})$ was also detected within $24 \mathrm{~h}$ in the closed reaction system, which may have originated from the decomposition of a trace amount of the unconverted $\mathrm{N}_{2} \mathrm{H}_{3}$ intermediate.

\section{Conclusions}

In summary, bismuth monoxide quantum dots were successfully synthesized by a facile hydrothermal synthesis method using oleate as the capping agent. Different from the other previously reported $\mathrm{N}_{2}$ reduction photocatalysts which have limited and randomly distributed defect-type $\mathrm{N}_{2}$ activation centers, the BiO catalyst has all of the lattice bismuth species as potential activation centers. This characteristic makes the assynthesized BiO a highly efficient photocatalyst for solar $\mathrm{N}_{2}$ reduction to ammonia. The ammonia synthesis rate is up to $1226 \mu \mathrm{mol} \mathrm{g}^{-1} \mathrm{~h}^{-1}$ without the assistance of any sacrificial agent or co-catalyst, which is about 1000 times higher than that of the previously reported traditional $\mathrm{Fe}^{-\mathrm{TiO}_{2}}$ photocatalyst. More importantly, the photocatalytic activity does not show obvious deactivation even after $120 \mathrm{~h}$. Kinetic studies by electrochemical measurements and quantum chemical calculations indicate that the highly improved photocatalytic performance of $\mathrm{BiO}$ may be ascribed to the synergy of the three low valence surface Bi(II) species for $\mathrm{N}_{2}$ activation. This study may open up new opportunities for designing highly efficient and robust solar light photocatalysts for artificial ammonia synthesis under ambient conditions.

\section{Acknowledgements}

This work was financially supported by the National Basic Research Program of China (2013CB933200), National Natural Science Foundation of China (21671197, 51272269, 51272303, 51472260), and the research grant (16ZR1440800) from Shanghai Science and Technology Commission. Prof. Guangyu Li from Shanghai Institute of Organic Chemistry is gratefully acknowledged for measurement and interpretation of the NMR data.

\section{References}

1 T. Rosswall, in Some Perspectives of the Major Biogeochemical Cycles, ed. G. E. Likens, Wiley, New York, 1981, Ch. 2.

2 J. B. Howard and D. C. Rees, Chem. Rev., 1996, 96, 2965-2982.

3 B. M. Hoffman, D. R. Dean and L. C. Seefeldt, Acc. Chem. Res., 2009, 42, 609-619.

4 R. Navarro-González, C. P. McKay and D. N. Mvondo, Nature, 2001, 412, 61-64.

5 S. Gambarotta and J. Scott, Angew. Chem., Int. Ed., 2004, 43, 5298-5308.

6 A. J. Pool, E. Lobkovsky and P. J. Chirik, Nature, 2004, 427, 527-530.

7 V. Smil, Enriching the Earth: Fritz Haber, Carl Bosch and the Transformation of World Food Production, MIT Press, Cambridge, MA, 2001.

8 C. Sivasankar, S. Baskaran, M. Tamizmani and K. Ramakrishna, J. Organomet. Chem., 2014, 752, 44-58.

9 R. Schlögl, Angew. Chem., Int. Ed., 2003, 42, 2004-2008.

$10 \mathrm{H}$. Bielawa, O. Hinrichsen, A. Birkner and M. Muhler, Angew. Chem., Int. Ed., 1999, 40, 1061-1063.

11 T. Shima, S. Hu, G. Luo, X. Kang, Y. Luo and Z. Hou, Science, 2013, 340, 1549-1552.

12 Y. Tanabe and Y. Nishibayashi, Coord. Chem. Rev., 2013, 257, 2551-2564.

13 G. N. Schrauzer and T. D. Guth, J. Am. Chem. Soc., 1977, 99, 7189-7193.

14 E. Endoh, J. K. Leland and A. J. Bard, J. Phys. Chem., 1986, 90, 6223-6226. 
15 H. Li, J. Shang, Z. Ai and L. Zhang, J. Am. Chem. Soc., 2015, 137, 6393-6399.

16 H. Kisch, Angew. Chem., Int. Ed., 2013, 52, 812-847.

17 V. Augugliaro, A. Lauricella, L. Rizzuti, M. Schiavello and A. Sclafani, Int. J. Hydrogen Energy, 1982, 7, 845-850.

18 J. Soria, J. C. Conesa, V. Augugliaro, L. Palmisano, M. Schiavello and A. Sclafani, J. Phys. Chem., 1991, 95, 274282.

19 O. P. Linnik and H. Kisch, Mendeleev Commun., 2008, 18, 10 11.

20 L. Palmisano, V. Augugliaro, A. Sclafani and M. Schiavello, J. Phys. Chem., 1988, 92, 6710-6713.

21 K. Tennakone, S. Punchihewa and R. Tantrigoda, Sol. Energy Mater., 1989, 18, 217-221.

22 O. Rusina, A. Eremenko, G. Frank, H. P. Strunk and H. Kisch, Angew. Chem., Int. Ed., 2001, 40, 3993-3995.

23 W. Zhao, J. Zhang, X. Zhu, M. Zhang, J. Tang, M. Tan and Y. Wang, Appl. Catal., B, 2014, 144, 468-477.

24 G. Dong, W. Hob and C. Wang, J. Mater. Chem. A, 2015, 3, 23435-23441.

25 M. Kitano, Y. Inoue, Y. Yamazaki, F. Hayashi, S. Kanbara, S. Matsuishi, T. Yokoyama, S. W. Kim, M. Hara and H. Hosono, Nat. Chem., 2012, 4, 934-940.

26 G. Ertl, Angew. Chem., Int. Ed., 2008, 47, 3524-3535.

27 M. M. Rodriguez, E. Bill, W. W. Brennessel and P. L. Holland, Science, 2011, 334, 780-783.
28 K. Arashiba, Y. Miyake and Y. Nishibayashi, Nat. Chem., 2011, 3, 120-125.

29 B. A. MacKay and M. D. Fryzuk, Chem. Rev., 2004, 104, 385401.

30 A. Caselli, E. Solari, R. Scopelliti, C. Floriani, N. Re, C. Rizzoli and A. Chiesi-Villa, J. Am. Chem. Soc., 2000, 122, 3652-3670.

31 K. Maeda, T. Takata, M. Hara, N. Saito, Y. Inoue, H. Kobayashi and K. Domen, J. Am. Chem. Soc., 2005, 127, 8286-8287.

32 S. Sun, W. Wang, D. Li and L. Zhang, ACS Catal., 2014, 4, 3498-3503.

33 J. Medina-Ramos, J. L. DiMeglio and J. Rosenthal, J. Am. Chem. Soc., 2014, 136, 8361-8367.

34 L. Liang, F. C. Lei, S. Gao, Y. F. Sun, X. C. Jiao, J. Wu, S. Qamar and Y. Xie, Angew. Chem., Int. Ed., 2015, 54, 13971-13974.

35 E. Laviron, J. Electroanal. Chem. Interfacial Electrochem., 1974, 52, 355-393.

36 L. Pospíšil, J. Bulíčková, M. Hromadová, M. Gál, S. Civiš, J. Cihelka and J. Tarábek, Chem. Commun., 2007, 2270-2272.

37 A. Watanabe and H. Kozuka, J. Phys. Chem. B, 2003, 107, 12713-12720.

38 Y. Matsumoto, J. Solid State Chem., 1996, 126, 227-234.

39 N. Bauer, J. Phys. Chem., 1960, 64, 833-837.

40 B. Ruscic and J. Berkowitz, J. Chem. Phys., 1991, 95, 43784384 . 